\title{
Eugenia aurata and Eugenia punicifolia HBK inhibit inflammatory response by reducing neutrophil adhesion, degranulation and NET release
}

Mírian Feliciano Costa', Tais lara Jesus ${ }^{1}$, Bruno Rafael Pereira Lopes ${ }^{1}$, Célio Fernando Figueiredo Angolini ${ }^{2}$, Abner Montagnolli', Lorraine de Paula Gomes ${ }^{1}$, Gabriela Sterle Pereira', Ana Lucia Tasca Gois Ruiz ${ }^{3}$, João Ernesto Carvalho ${ }^{4}$, Marcos Nogueira Eberlin², Catarina dos Santos ${ }^{1}$ and Karina Alves Toledo ${ }^{{ }^{*}}$

\begin{abstract}
Background: Eugenia spp. are used in popular medicine in the treatment of pain, diabetes, intestinal disorders and cough. The aim of the work is to evaluate, ex vivo and in vivo, the anti-inflammatory activity of the hydroethanolic extracts of the leaves of Eugenia aurata (EA) and Eugenia punicifolia HBK (EP) upon neutrophils.

Methods: Ex vivo, isolated human neutrophils were sensitized by Eugenia extracts $(0.1-1000 \mu \mathrm{g} / \mathrm{mL})$ and stimulated by PMA. In these conditions, different neutrophil activities related to inflammatory process were measured: adhesion, degranulation and NET release. Neutrophil viability and tumor line cells were monitored. In vivo, neutrophil influx was evaluated by peritonitis model performed in mice pretreated with different concentrations of Eugenia extracts. Phytochemical profile was assessed by mass spectrometry.

Results: Ex vivo, EA and EP $(1000 \mu \mathrm{g} / \mathrm{mL})$ reduced cell adhesion and degranulation, respectively. NET release was inhibited by EA and EP. Anti-inflammatory activities occurred in the absence of cytotoxicity. In vivo, both EA as EP inhibited neutrophil migration. The phytochemical profile revealed that EA contains myricitrin, rutin, quinic acid and quercetin derivatives. EP presents gallic acid, quercetin derivatives, syringic acid, ellagic acid, monogalloyl-glucose, glycosyringic acid, mudanoside B, HHDP glucose isomer and digalloylglucose isomer. EA and EP inhibit neutrophil migration by different pathways.
\end{abstract}

Conclusion: Different chemical compositions may explain the anti-inflammatory effects described herein for EA and EP. Both extracts inhibit NET release but only EA reduces cell adhesion whereas EP decreases elastase secretion. This work contributes to the elucidation of cellular mechanisms related to the anti-inflammatory activity for leaves of $E$. aurata and E. punicifolia HBK.

Keywords: Inflammation, Neutrophils, Eugenia aurata, Eugenia punicifolia (HBK), Adhesion, Elastase

\footnotetext{
* Correspondence: karinalves@assis.unesp.br

'Departamento de Ciências Biológicas, Faculdade de Ciências e Letras,

Universidade Estadual Paulista -UNESP, Av Dom Antônio, 2100, Parque

Universitário, ZIP 19806-900 Assis, SP, Brazil

Full list of author information is available at the end of the article
} 


\section{Background}

Inflammation is a process that includes a complex immune response, which occurs in several steps and may be caused by chemical, physical, microbiological and immunological stimuli. It involves leukocyte recruitment where the first leukocytes to be recruited and act on the inflamed tissue are neutrophils. Neutrophils have been considered a target for pharmacological intervention given their abilities to kill microorganisms, to begin and amplify the inflammatory process. Neutrophil recruitment and inflammatory activities require a complex sequence of events, including cell adhesion, degranulation, and more recently, neutrophil extracellular traps (NET) release [1]. The control of the inflammatory process is critical because of the associated risks: tissue damage, loss of organ performance and failure.

Eugenia genus with over 500 species, of which about 400 are in Brazil, assumes prominence in popular medicine, mainly for their anti-inflammatory activities in the treatment of wounds and infections [2, 3]. Flavonoids, tannins, terpenoids and essentials oils were isolated from this genus $[4,5]$. Different crude extracts of Eugenia show several medicinal effects, such as anti-inflammatory [6], antifungal [7], neurological [8], antimicrobial [9], among others. Leaves of Eugenia punicifolia are popularly used to treat inflammation [10], diabetes $[6,10]$, fever and flu $[11,12]$. E. aurata is an endangered species [13] with low studies in the literature and, by analogy, there is a need of registering its effects on inflammatory processes.

Although leaves of Eugenia species are widely used in popular medicine for inflammatory diseases, efficacy of cellular and molecular mechanisms remains elusive. Our aim was to evaluate the cellular mechanisms involved in the anti-inflammatory activity of Eugenia aurata and Eugenia punicifolia. For this purpose, ex vivo assays were performed and the anti-inflammatory activity was confirmed using in vivo assays.

\section{Methods}

\section{Collection and preparation of extract}

Leaves of E. punicifolia and E. aurata were collected in December (2009) in Assis (Instituto Florestal e Estações Experimentais - Floresta Estadual de Assis) at the point (UTM 0561750 L/O 7500935 (+/- 3 m) - 0559055 L/O 7499970 (+/- 4 m)), São Paulo State, Brazil. Dr. Antônio C.G. Melo identified the specimen and voucher specimen $\left(n^{\circ} 43.522\right.$ and 43520, respectively) were deposited in Herbarium D. Bento Pickel for future reference. The extract has been prepared with $10 \mathrm{~g}$ of plant material (dried and triturated leaves) and $100 \mathrm{ml}$ of solvent (Ethanol: $\mathrm{H}_{2} \mathrm{O} 70: 30 \mathrm{v} / \mathrm{v}$ ). The extract solution was obtained by $2 \mathrm{~h}$ dynamic maceration at room temperature $\left(25 \pm 2{ }^{\circ} \mathrm{C}\right)$, followed by filtration. Remaining extract residue filtration was carried twice by the same procedure. Subsequently, the solution was dried at $40{ }^{\circ} \mathrm{C}$ temperature with a rotary evaporator, obtaining $45 \%$ and $7 \%$ hydroethanolic extract solutions from E. punicifolia (HEEP) and E. aurata (HEEA), respectively. The hydroethanolic extract fraction soluble in Phosphate Buffer Solution (PBS; $137 \mathrm{mM} \mathrm{NaCl}$,

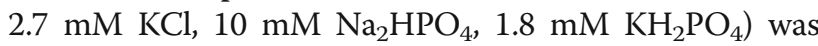
evaluated in all bioassays (Eugenia aurata = EA; Eugenia punicifolia $=\mathrm{EP})$.

\section{Animals}

Swiss male mice, weighing on average 40 grams, were kept in controlled temperature rooms $\left(23-25^{\circ} \mathrm{C}\right)$ with access to food and water. All animal care and experimental procedures were performed in accordance with the internationally accepted principles for laboratory animal use [14].

\section{Human neutrophils isolation}

Human neutrophils were isolated and prepared according to previous methods described $[15,16]$. Cells were suspended in Hank's balanced salt solution (HANKS) (Sigma, St. Louis, MO, USA) containing $0.1 \%$ gelatin (w/v) (HANKS-gel) with over $90 \%$ viability as determined by the Trypan blue (Sigma) exclusion test, and 90-95\% of cells were found to be neutrophils.

\section{Cell viability (MTT assay)}

Cytotoxicity was evaluated by the colorimetric method of MTT (3-(4,5-dimethylthiazol-2-yl) 2,5-Diphenyl Tetrazolium bromide) (Sigma), which consists of indirectly measuring of cell viability by mitochondrial enzyme activity of living cells. Human neutrophils ( $2 \times 10^{5} /$ well) seeded into 96 well culture plates were incubated with different concentrations of Eugenia spp. during $1 \mathrm{~h}$ at $37{ }^{\circ} \mathrm{C}$. Subsequently, MTT (1 mg/mL) was added to each well and incubated at $37^{\circ} \mathrm{C}$ for $4 \mathrm{~h}$. After incubation, formazan crystals were diluted by addition of Dimethyl Sulfoxide (DMSO, Sigma) and the optical density (O.D.) of samples measured in a spectrophotometer at $570 \mathrm{~nm}$. Neutrophils incubated either with RPMI-1640 (Sigma) or $50 \mu \mathrm{M} \mathrm{H}_{2} \mathrm{O}_{2}$ [17] were used as negative and positive control (100\% viable) to cell death, respectively.

\section{Cell adhesion}

Cell adhesion assays were performed in 96 well micro plates. Human neutrophils $\left(4 \times 10^{5}\right)$ suspended in RPMI medium (Sigma) plus $5 \%$ Fetal Bovine Serum (FBS) (Vitrocell, Campinas, SP, Brazil) were added to wells of a micro plate containing different concentrations of Eugenia spp. After $15 \mathrm{~min}$, cells were then stimulated by Phorbol Myristate Acetate (PMA 25nM) (Sigma) for $1 \mathrm{~h}$ at $37{ }^{\circ} \mathrm{C}$. Non-adherent cells were removed and adherent cells were made evident via a colorimetric test with 
Bicinchoninic Acid (BCA; Pierce). Sample absorbance was measured in a Multiskan FC (Thermo Scientific, Waltham, MA, USA) reader at $560 \mathrm{~nm}$.

\section{Elastase activity}

Elastase enzyme activity upon degranulation was assessed as follows: Neutrophils $\left(2 \times 10^{5}\right)$ suspended in Hank's solution were incubated for $30 \mathrm{~min}$ in the presence of different Eugenia spp. concentrations then stimulated with PMA $(25 \mathrm{nM})$ for $3 \mathrm{~h}$ at $37^{\circ} \mathrm{C}$. Succeeding incubation, neutrophils were centrifuged (437 x g, $5 \mathrm{~min}$ ) and the resulting supernatants incubated in $1 \mathrm{mM}$ elastase substrate $(\mathrm{N}-$ Methoxysuccinyl-Ala-Ala-Pro-Val p-nitroanilide) (Sigma) for $30 \mathrm{~min}$. After incubation, color reaction was measured at $405 \mathrm{~nm}$ on microplate reader Multiskan FC (Thermo Scientific). Several concentrations of purified elastase enzyme from human neutrophils (EMD Chemicals Inc., Billerica, MA, USA) were used as standards.

\section{Neutrophil Extracellular Traps (NETs) release}

Human neutrophils $\left(2 \times 10^{5}\right)$ were incubated with different concentrations of Eugenia spp. during $30 \mathrm{~min}$ and then stimulated with PMA (50 nM) for $4 \mathrm{~h}$ at $37^{\circ} \mathrm{C}$. NETs generated by activated neutrophils were digested with $500 \mathrm{mU} / \mathrm{mL}$ micrococcal nuclease (MNase, Worthington Biochemical Corp.) [18]. The nuclease activity was ceased by $5 \mathrm{mM}$ Ethylene Diamine Tetra Acetic Acid (EDTA) and the culture supernatant collected and stored at $4{ }^{\circ} \mathrm{C}$ until the moment of quantification. NETs were quantified using the PicoGreen dsDNA kit (Invitrogen) according to the manufacturer's recommendations.

\section{Peritonitis model (in vivo)}

Mice received $1 \mathrm{~mL}$ of $3 \%$ Thioglycolate injected intraperitoneally one hour after plant extract subcutaneous administration (3-300 mg/kg) [19, 20]. Six hours later, mice were euthanized by cervical dislocation. The cells were immediately harvested with $5 \mathrm{~mL}$ PBS containing heparin $(5 \mathrm{IU} / \mathrm{mL})$. Total counts of harvested cells were performed in a Neubauer chamber. Differential counts were made on smears stained using Panoptic Fast Stain (LaborClin, Siqueira Campos, PR, Brazil). The results were reported as the number of neutrophils per $\mathrm{mL}$ of cavity wash. The control groups animals received: (1) subcutaneous and intraperitoneal PBS injection; (2) subcutaneous PBS and intraperitoneal Thioglycolate injection; (3) subcutaneous Dexamethasone $(0.5 \mathrm{mg} / \mathrm{kg})$ and intraperitoneal Thioglycolate injection.

\section{Evaluation of antiproliferative activity in vitro}

Antiproliferative activity was tested against cell lines: UACC-62 (melanoma); MCF-7 (mammary); NCI-ADR/ RES (drug resistant ovary); 786-0 (kidney); NCI-H460 (lung); PC-3 (prostate); OVCAR-3 (ovary); HT-29 (colon),
K562 (leukemia) and VERO (African green monkey kidney cell line). Stock cultures were grown in a medium containing $5 \mathrm{~mL}$ RPMI 1640 (Sigma) supplemented with $5 \%$ fetal bovine serum. Gentamicin $(50 \mathrm{mg} / \mathrm{mL})$ was added to experimental cultures. Cells in 96 well plates (100 $\mu \mathrm{L}$ cells/well) were exposed to sample concentrations of DMSO/RPMI $(0.25,2.5,25$, and $250 \mu \mathrm{g} / \mathrm{mL})$ at $37{ }^{\circ} \mathrm{C}$, $5 \% \mathrm{CO}_{2}$ in air for $48 \mathrm{~h}$. Next, cells were fixed with $50 \%$ trichloroacetic acid and cell proliferation was determined employing sulforhodamine B assay at $540 \mathrm{~nm}$ [21]. Using the concentration-response curve for each cell line, TGI (concentration that produces total growth inhibition or cytostatic effect) was determined through non-linear regression analysis, utilizing software ORIGIN 8.5 (OriginLab Corporation) [22].

\section{Phenolic content}

Phenolic content was performed as previously described [23] with minor adaptations. Briefly, $2.5 \mathrm{~mL}$ FolinCiocalteau $10 \%(\mathrm{v} / \mathrm{v})$ and $2.0 \mathrm{~mL} 4 \%(\mathrm{~m} / \mathrm{v})$ sodium carbonate were added to a $0.5 \mathrm{~mL}$ extract in ethanol solution $(1 \mathrm{mg} / \mathrm{mL})$. After a $2 \mathrm{~h}$ incubation in the dark, at room temperature, absorbance was measured at $750 \mathrm{~nm}$ and results were expressed as equivalent milligrams of gallic acid per gram of sample. All tests were performed in triplicate.

\section{Flavonoid content}

Flavonoid content was performed as previously described [23] with minor adaptations. Briefly, $1.5 \mathrm{~mL}$ ethanol, $0.1 \mathrm{~mL}$ potassium acetate $(1 \mathrm{M})$ and $2.8 \mathrm{~mL}$ distilled water were added to a $0.5 \mathrm{~mL}$ extract in ethanol solution $(1 \mathrm{mg} / \mathrm{mL})$. After $30 \mathrm{~min}$ incubating in the dark at room temperature, absorbance was measured at $425 \mathrm{~nm}$ and results were expressed as equivalent milligrams of quercetin acid per gram of sample. All tests were performed in triplicate.

\section{ESI-MS ${ }^{n}$ analysis}

The mass spectrometry experiments were performed on a 6550 iFunnel Q-TOF (Agilent Technologies). The studied matrix was analyzed by Dual Agilent Jet Stream ESI (Dual-AJS-ESI) (ESI) and fragmented in the MS/MS collision cell. The negative mode was selected for the generation and analysis of first order mass spectra (MS) and the remaining multistage experiments under the following conditions: Gas Temp at $290{ }^{\circ} \mathrm{C}$, Drying Gas flow at $11 \mathrm{Lmin}^{-1}$, Nebulizer at $45 \mathrm{psi}$, Sheath gas temp at $350{ }^{\circ} \mathrm{C}$, Sheath gas flow $12 \mathrm{Lmin}^{-1}$, VCap 3000, Nozzle voltage 320 V, Fragmentor 100 V, OCT 1 RFVpp $750 \mathrm{~V}$, and collision energy $35 \mathrm{~V}$ Agilent MassHunter Qualitative Analysis software version B.06.00 used for data acquisition and processing. 


\section{Statistical analysis}

Experimental data was evaluated by variance analysis (one-way ANOVA) followed by Bonferroni test. A significance level of $5 \%$ was adopted. All assays were performed in triplicate at least in three independent assays.

\section{Results and discussion}

Inflammatory process involves cellular and molecular events that begin with neutrophil recruitment. This process is commonly separated in four steps: rolling, adhesion, transmigration and degranulation. The rolling is mediated by the interaction between neutrophil selectins (selectin- L) and endothelium selectin (selectins $\mathrm{P}$ and E). Sequentially, the adhesion happens by the interaction between endothelium and neutrophil integrins as well as by mobilization of neutrophil secretory vesicles. After that, the transmigration - or diapedesis - also occurs under effect of integrins interactions and counting on the help of release of neutrophil tertiary granules to digest endothelium basal membrane. Finally, the proteins released from neutrophil secondary/primary granules can be associated with DNA and oxidative enzymes, also called NETs. The release of NETs improves microbe capture, as well as increases phagocytosis efficiency $[1,24]$.

The cellular mechanisms related to the anti-inflammatory activity of E. punicifolia (EP) and E. aurata (EA) were evaluated. Therefore, some neutrophil functions were analysed ex vivo and others in vivo because neutrophils are the first inflammatory cells to be recruited to the damaged tissue. Both Eugenia extracts were able to inhibit neutrophils responses, by different pathways, under clear evidence of no toxicity for the cells.

Ex vivo assays aimed the evaluation of the role of $E A$ and $E P$ in adhesion, elastase secretion and NET release. In the first step, adhesion, neutrophils incubated with 25 nM PMA and adhered to the culture plate were considered as $100 \%$ adhesion (Fig. 1). Neutrophils incubated only with culture medium RPMI-1640 showed basal adhesion rate $(\sim 50 \%)$. Pretreatment of neutrophils with several EP concentrations did not alter their ability to adhere under PMA stimulus. On the other hand, pretreatment with EA $1000 \mu \mathrm{g} / \mathrm{mL}$ significantly reduced cell adhesion. EP $(1000 \mu \mathrm{g} / \mathrm{mL})$ was the only concentration able to induce a weak neutrophil adhesion when neutrophils were incubated with extracts alone (data not shown), although this effect has not been statistically significant.

The second step was to evaluate elastase secretion, indirectly assessed through elastase enzyme activity. Supernatants of cultures of neutrophils stimulated by PMA $(25 \mathrm{nM})$ and previously sensitized by plant extracts were analyzed. The release of elastase induced by PMA was considered as100\%. Neutrophils incubated with medium alone showed significant reduction (Fig. 2). The

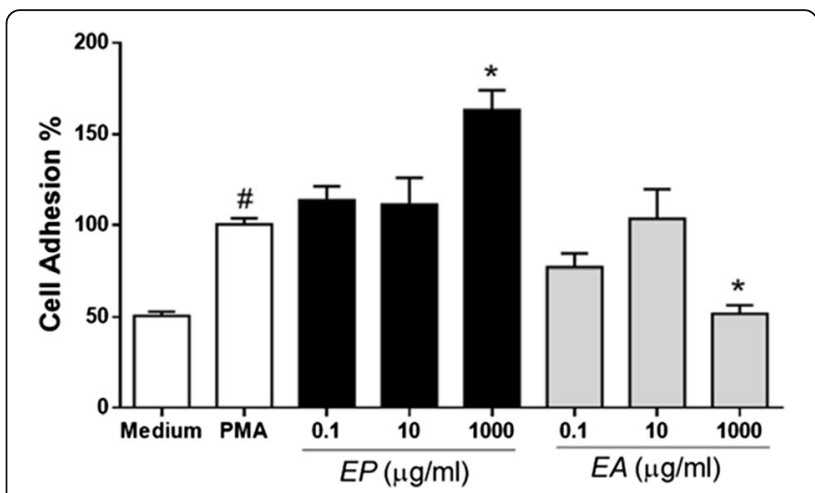

Fig. 1 Eugenia aurata (EA) inhibits human neutrophil adhesion. Human neutrophils $\left(4 \times 10^{5}\right)$ were pretreated with different concentrations of EA or EP (15 min) and stimulated (1 h) to adhesion by PMA (25nM). Neutrophils incubated with RPMI alone were used as negative control. Data are shown as cell adhesion (\%) \pm S.D. where PMA is $100 \% . p<0.05$ when compared to PMA (*) or medium (\#) control

presence of EA did not alter elastase secretion at any tested concentration. However, EP $1000 \mu \mathrm{g} / \mathrm{mL}$ significantly reduced PMA induced elastase secretion. None of the extract concentrations in test was able to induce elastase secretion (data not shown).

Next inflammatory event evaluated was the release of NETs. The presence of both plant extracts studied here inhibited significantly the release of NETs induced by PMA (50nM) for all tested concentrations $(0.1-1000 \mu \mathrm{g} /$ $\mathrm{mL}$ ) (Fig. 3). The positive control (50nM PMA) induced DNA release of $230 \mathrm{ng} / \mathrm{ml}$ while negative control (Medium) showed $\sim 50 \mathrm{ng} / \mathrm{mL}$. The inhibition of this event may have a suppressive effect on inflammation, activation of neutrophils and capture/elimination of pathogens by decreasing the inflammatory stimulus that comes from genetic material released. Furthermore, the

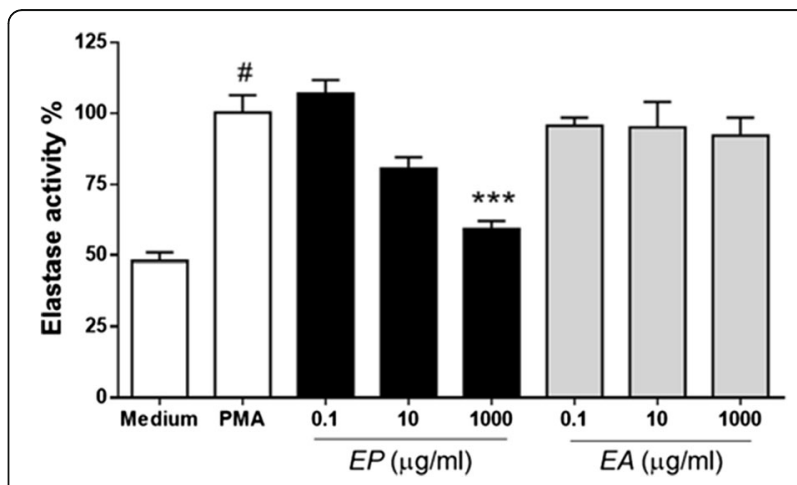

Fig. 2 Eugenia punicifolia (EP) inhibits human neutrophil elastase secretion. Human neutrophils $\left(4 \times 10^{5}\right)$ were pretreated with different concentrations of EA or EP (30 min) and stimulated to degranulation by PMA (25nM) for 3 h. Neutrophils incubated with only Hank's (medium) were used as negative control. Data shown Elastase activity (\%) \pm S.D. where PMA is $100 \%$. $p<0.01$ when compared to PMA $(* *)$ or medium (\#\#) control 


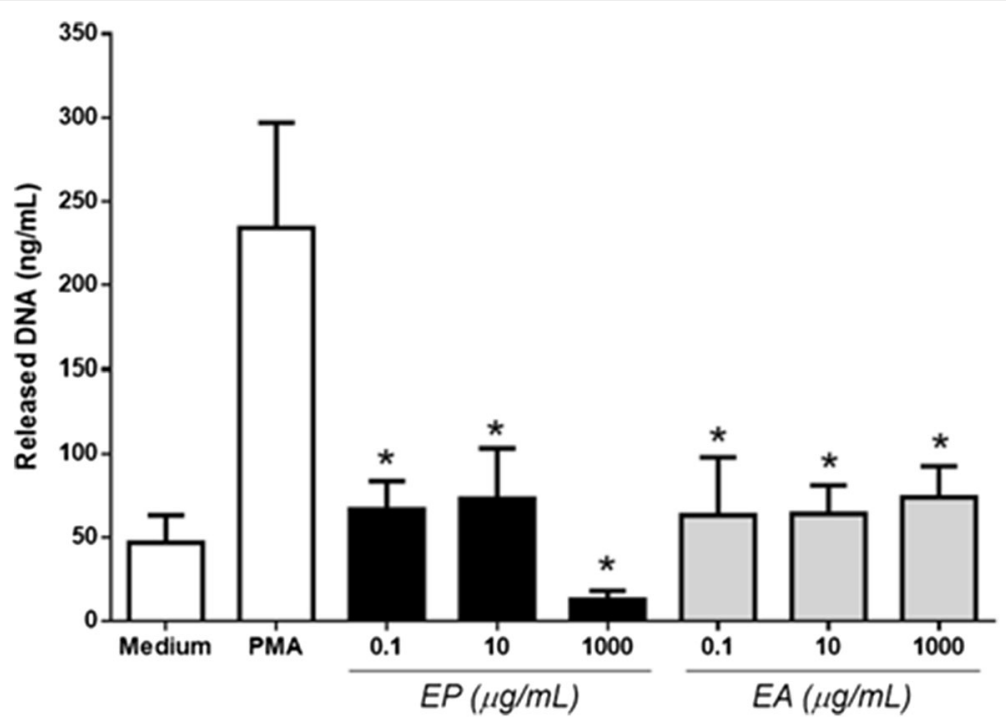

Fig. 3 Eugenia spp. extracts inhibit NET release induced by PMA. Human neutrophils (4x105) were pretreated with different concentrations of $E$. aurata $(E A)$ or E.punicifolia (EP) $(0.1-1000 \mu \mathrm{g} / \mathrm{mL})$ and stimulated to NET release for $4 \mathrm{~h}$ by 50nM PMA. Neutrophils incubated with PMA or Hank's (medium) alone were used as positive and negative control, respectively. Data shown as released DNA $(\mathrm{ng} / \mathrm{mL}) \pm$ S.D. $p<0.01$ when compared to PMA $(*)$ or medium (\#) control

presence of extracellular DNA (NETs) has been appointed as a direct source of stimulus to inflammatory and autoimmune diseases [1].

Neutrophil viability was monitored during all ex vivo assays. This is an important factor once some inhibitory effects could be related to cytotoxicity. The viability was assessed by MTT assay. The data revealed that the extracts, evaluated in different concentrations $(0.1-1000$ $\mathrm{ug} / \mathrm{mL}$ ), did not reduce neutrophil viability when these cells were sensitized either with EP or with EA (Fig. 4). As positive and negative controls, $\mathrm{H}_{2} \mathrm{O}_{2}$ and RPMI medium were used. $\mathrm{H}_{2} \mathrm{O}_{2}(50 \mu \mathrm{M})$ reduced $70 \%$ of cell viability.

Since no cytotoxic effects were observed in leukocytes, other cytotoxicity assays were performed with E. punicifolia

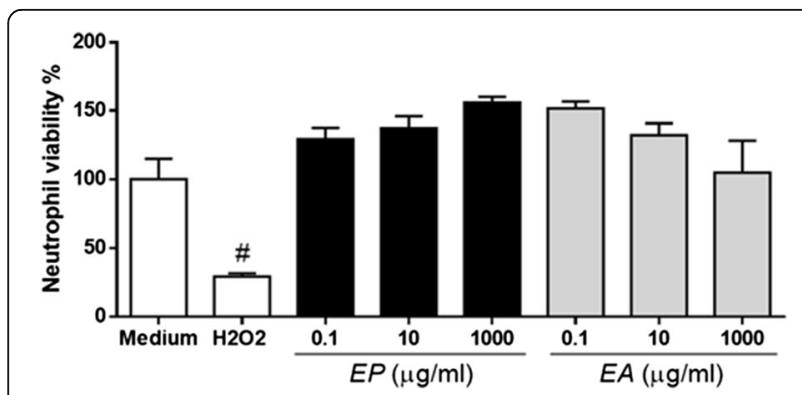

Fig. 4 Neutrophils viability is not affected by Eugenia aurata (EA) or E. punicifolia (EP). Human neutrophils $\left(4 \times 10^{5}\right)$ were incubated with different concentrations of EA or EP. At the end of incubation, cell viability was measured by MTT assay. Neutrophils incubated with RPMI (medium) alone or $50 \mu \mathrm{M} \mathrm{H}_{2} \mathrm{O}_{2}$ (Hydrogen Peroxide) were used as negative and positive control, respectively. Data shown as Neutrophil viability (\%) \pm S.D. $p<0.01$ when compared to Medium (*) hydroethanolic extract solutions (HEEP) as well as with $E$. aurata hydroethanolic extract solutions (HEEA), using tumor and not tumor cell lines. As others [25], HEEP and HEEA (mean TGI $>141 \mu \mathrm{g} / \mathrm{mL}$ and $198 \mu \mathrm{g} / \mathrm{mL}$, respectively) did not exhibit a cytotoxicity against all tested cell lines. HEEP presented a moderate selective activity effect against cell line K562 (leukemia, $12.9 \pm 7.19 \mu \mathrm{g} / \mathrm{mL}$ ) and weak for MCF-7 (mammary, $39.0 \pm 5.80 \mu \mathrm{g} / \mathrm{mL}$ ). For all the analyzed lineages, including normal cell VERO (Green monkey kidney), HEEP was inactive (Table 1). HEEA was inactive for the tested lineages, including normal cell VERO (Green monkey kidney).

According to ex vivo assays, E.aurata and E.punicifolia inhibit neutrophil functions in the absence of cell death. Based on these results, in vivo tests were performed. The in vivo experiment comprises a greater complexity of events when compared to in vitro and ex vivo experiments, in which experimental conditions are better monitored. Therefore, the results obtained using in vivo analyses are closer to the real scenario.

Acute peritonitis model induced by Thioglycolate in mice was assessed in order to evaluate Eugenia anti-inflammatory activity. Both extracts showed anti-inflammatory effect by inhibiting neutrophil influx. No animal showed symptoms of toxicity or even death. Mice received a subcutaneous injection of extract, and $1 \mathrm{~h}$ later were administered with $3 \%$ Thioglycolate (TG) intraperitoneally. When mice are assayed in a peritonitis model, a $6 \mathrm{~h}$ period is necessary to reach maximum acute neutrophil recruitment. In vivo cell migration analysis showed that subcutaneous injection of different extracts concentrations significantly reduced cell 
Table $1 \mathrm{TGl}$ values (Total Growth Inhibition, $\mu \mathrm{g} / \mathrm{mL}$ ) of Eugenia punicifolia and E. aurata hydroethanolic leaf extracts

\begin{tabular}{|c|c|c|c|c|c|c|c|c|c|c|}
\hline \multirow[t]{2}{*}{ Tested material } & \multicolumn{10}{|c|}{ Cell lines $^{a}$} \\
\hline & u & $M$ & a & 7 & 4 & $p$ & o & h & k & V \\
\hline Doxorubicin $^{b}$ & & 3.30 & 6.60 & 2.67 & 0.90 & 5.85 & 2.95 & 3.90 & 8.43 & 8.43 \\
\hline HEEP & $>250$ & $39.0 \pm 5.80$ & $120.0 \pm 0.97$ & $>250$ & $209.7 \pm 3.26$ & $47.6 \pm 13,3$ & $105 \pm 53,7$ & $124.7 \pm 0.99$ & $12.9 \pm 7.19$ & $>250$ \\
\hline HEEA & * & $>250$ & $>250$ & $240 \pm 0.14$ & $78.5 \pm 21.7$ & $229 \pm 64$ & * & $>250$ & $34.2 \pm 9.7$ & $>250$ \\
\hline
\end{tabular}

${ }^{a} \mathrm{u}=$ UACC (melanoma); $\mathrm{m}=\mathrm{MCF}-7$ (mammary); $\mathrm{a}=\mathrm{NCl-ADR/RES} \mathrm{(drug} \mathrm{resistant} \mathrm{ovary);} 7=786-0$ (kidney); $4=\mathrm{NCl}-\mathrm{H} 460$ (lung); $\mathrm{p}=\mathrm{PC}-3$ (prostate); $\mathrm{o}=\mathrm{OVCAR}-3$ (ovary); $\mathrm{h}=\mathrm{HT}-29$ (colon) V = VERO (Green monkey kidney). ${ }^{\mathrm{b}}$ Positive Control. ${ }^{\mathrm{C}} \mathrm{HEEP}$ and HEEA - Ethanol:water 70:30 v/v extract. ${ }^{*}$ not tested

influx into the peritoneal cavity (Fig. 5). EP showed antiinflammatory activity at concentrations of 30 and $300 \mathrm{mg} /$ $\mathrm{mL}$ (Fig. 5a). As for EA, the anti-inflammatory activity was observed for all the tested concentrations (Fig. 5b). As negative control, extracts were s.c. injected and PBS was i.p. injected. As a result, neutrophil migration did not occur. Either for EA as for EP, the anti-inflammatory activity was comparable to the effect of dexamethasone (DEX), a potent anti-inflammatory drug in clinical use.

Differences in chemical composition between $E$. aurata and E. punicifolia HBK may explain the anti-

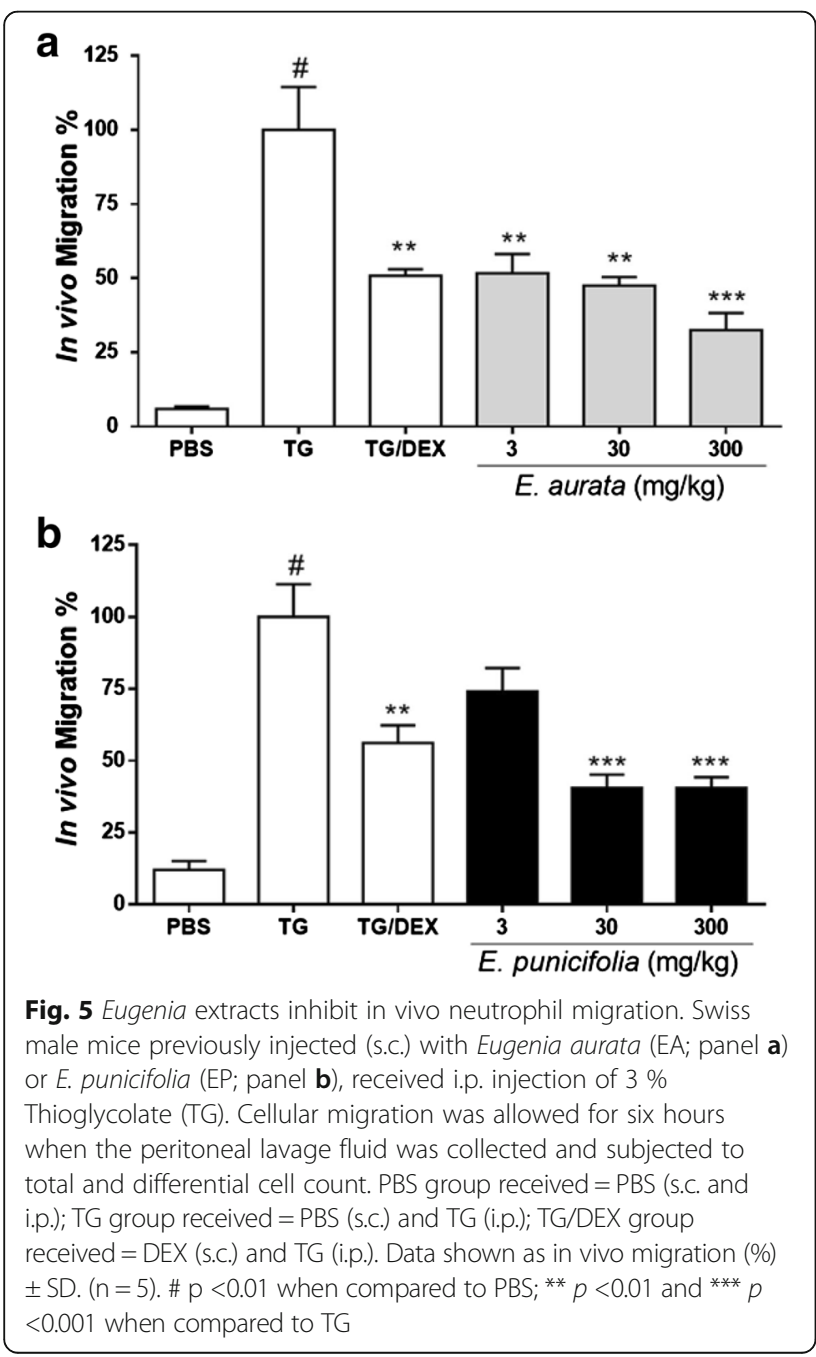

inflammatory effects described herein. Both extracts inhibit NET release but only EA reduces cell adhesion whereas EP decreases elastase secretion.

The control of accute/chronic inflammatory processes as rheumatoid arthrite, ashtma, vaculitis among others like diabetes is relevant, once such processes may be related to the damage caused by the release of free radicals [26]. Moreover, neutrophil activation is largely dependent on the generation of reactive oxygen species (ROS) that are known to be inhibited by antioxidant compounds, as catechin and rutin, found abundantly in plant extracts [27]. Selected phenolic compounds, as diosmin and hesperidin, decrease the adhesion of inflammatory cells to the endothelium [28], whereas others can inhibit degranulation of neutrophils without affecting superoxide production [29].

E. punicifolia showed phenolic compounds concentrations of $74.86 \pm 0.02 \mathrm{mg}$ gallic acid/g extract and $E$. aurata $57.93 \pm 0.05 \mathrm{mg}$ gallic acid/g extract. Flavonoid content found was $32.00 \pm 0.02 \mathrm{mg}$ quercetin/g extract and $15.78 \pm 0.01 \mathrm{mg}$ quercetin/g extract, respectively.

Magina et al. [30] described, respectively, for Eugenia brasiliensis, E.umbelliflora and E.beaurepaireana hydroethanolic leaves extracts (70 \%): $162.6 \pm 3.3,138.0 \pm 2.7$ to $128.1 \pm 2.9 \mathrm{mg}$ gallic acid/g. E. aurata and E. punicifolia showed lower phenol levels when compared to species studied by Magina et al. [30]. Although phenolic content found is lower than expected for E. punicifolia, flavonoid content approached similar levels to previous studies from Magina and collaborators [30]: E. brasiliensis, E. umbelliflora and E.beaurepaireana showed, respectively, 14.4 \pm $1.1,31.2 \pm 1.7$ and $10.4 \pm 1.1 \mathrm{mg}$ quercetin/g extract.

In addition, after assessing the phenolic and flavonoid contents, an ESI-MS was performed, in order to correlate the main secondary metabolites found in HEEP and in HEEA with their biological activity without further chromatographic separations, since a preliminary HPLC HEEP analysis was already published by our group [31]. Gallic acid derivatives, flavonols, glycosides and procyanidins were the most common phenolic compounds in fruits and leaves of the Myrtaceae family [32]. Database search showed no prior HEEA research published to the moment.

The most characteristic corresponding molecular formulas of HEEP and HEEA, their fractions, MS/MS fragments are shown in Table 2. All peaks found were 
Table 2 Phenolic compounds tentatively identified of Eugenia sp. leaf extracts

\begin{tabular}{|c|c|c|c|c|c|c|c|}
\hline Formula $[\mathrm{M}-\mathrm{H}]^{-}$ & Theoretical mass & $\begin{array}{l}\text { Experimental mass } \\
{[\mathrm{M}-\mathrm{H}]^{-} \mathrm{m} / \mathrm{z}}\end{array}$ & $\Delta \mathrm{m}(\mathrm{ppm})$ & MS/MS fragments $\mathrm{m} / \mathrm{z}$ & Compound identification & $\begin{array}{l}\text { HEEP } \\
\text { HEEA }\end{array}$ & $\begin{array}{l}\text { EA } \\
\text { EP }\end{array}$ \\
\hline $\mathrm{C}_{7} \mathrm{H}_{5} \mathrm{O}_{5}$ & 169,0142 & 169,0148 & $-1,49$ & 151,125 & gallic acid & HEEP & Ep \\
\hline $\mathrm{C}_{7} \mathrm{H}_{10} \mathrm{O}_{6}$ & 191,0561 & 191,0561 & 0,06 & 173,134 & quinic acid & HEEA & Ea \\
\hline $\mathrm{C}_{7} \mathrm{H}_{11} \mathrm{O}_{6}$ & 197,0458 & 197,0461 & $-1,28$ & $169,140,124$ & syringic acid & HEEP & Ep \\
\hline $\mathrm{C}_{14} \mathrm{H}_{5} \mathrm{O}_{8}$ & 300,9990 & 300,9996 & $-1,69$ & $284,257,229,185$ & ellagic acid & HEEP HEEA & Ep \\
\hline $\mathrm{C}_{13} \mathrm{H}_{15} \mathrm{O}_{10}$ & 331,0671 & 331,0670 & $-0,39$ & $271,211,169$ & monogalloyl-glucose & HEEP HEEA & Ep \\
\hline $\mathrm{C}_{15} \mathrm{H}_{20} \mathrm{O}_{10}$ & 359,0984 & 359,0979 & 1,31 & 271,169 & Glycosyringic acid & HEEP & Ep \\
\hline $\mathrm{C}_{17} \mathrm{H}_{19} \mathrm{O}_{9}$ & 367,1035 & 367,1050 & 0,29 & $326,193,173,134$ & 3-Feruloylquinic acid & HEEA & \\
\hline $\mathrm{C}_{19} \mathrm{H}_{13} \mathrm{O}_{12}$ & 433,0412 & 433,0423 & $-2,11$ & $300,169,125$ & Ellagic acid xyloside & HEEP & \\
\hline $\mathrm{C}_{20} \mathrm{H}_{17} \mathrm{O}_{11}$ & 433,0776 & 433,0768 & 2,52 & $300,271,169$ & $\begin{array}{l}\text { Quercetin-3-O-a- } \\
\text { arabinopyranoside }\end{array}$ & HEEP & Ep \\
\hline $\mathrm{C}_{21} \mathrm{H}_{19} \mathrm{O}_{11}$ & 447,0933 & 447,0936 & $-0,7$ & $301,271,151$ & $\begin{array}{l}\text { Quercetin-3-O- } \beta \text { - } \\
\text { rhamnose }\end{array}$ & HEEP HEEA & Ep Ea \\
\hline $\mathrm{C}_{21} \mathrm{H}_{19} \mathrm{O}_{12}$ & 463,0880 & 463,0882 & 0,43 & $317,271,179$ & myricitrin & HEEA HEEP & $\mathrm{Ea}$ \\
\hline $\mathrm{C}_{18} \mathrm{H}_{23} \mathrm{O}_{14}$ & 463,1166 & 463,1086 & 1,19 & 301,169 & Mudanoside B & HEEP & Ep \\
\hline $\mathrm{C}_{20} \mathrm{H}_{17} \mathrm{O}_{14}$ & 481,0624 & 481,0642 & $-3,78$ & $447,301,275,211,169$ & HHDP glucose isomer & HEEP & Ep \\
\hline $\mathrm{C}_{23} \mathrm{H}_{31} \mathrm{O}_{11}$ & 483,1872 & 483,1858 & 2,16 & $447,331,169$ & Digalloylglucose isomer & HEEP & Ep \\
\hline $\mathrm{C}_{27} \mathrm{H}_{30} \mathrm{O}_{15}$ & 593,1502 & 593,1547 & 1,67 & $415,341,284,103$ & rutinosylkaempferol & HEEA & \\
\hline $\mathrm{C}_{27} \mathrm{H}_{19} \mathrm{O}_{14}$ & 609,1480 & 609,1461 & $-3,1$ & $511,300,151$ & Rutin & HEEA & Ea \\
\hline $\mathrm{C}_{39} \mathrm{H}_{19} \mathrm{O}_{8}$ & 615,1087 & 615,1086 & $-0,1$ & $463,301,241,169$ & $\begin{array}{l}\text { Quercetin galloylhexoside } \\
\text { isomer }\end{array}$ & HEEP & Ea Ep \\
\hline $\mathrm{C}_{34} \mathrm{H}_{24} \mathrm{O}_{22}$ & 783,0686 & 783,0681 & 0,7 & $481,381,275$ & bis HHDP-glucose isomer & HEEP & \\
\hline
\end{tabular}

$\mathrm{Ep}=E$. punicifolia; $\mathrm{Ea}=E$. aurata (HEEP and HEEA fraction soluble in ethanolic solution)

tentatively assigned based on their accurate masses and MS/MS patterns. The peak at $m / z 169$ was assigned to gallic acid and confirmed by fragmentation of $\mathrm{m} / \mathrm{z} 125$ [M-44-H] $]^{-}$because of $\mathrm{CO}_{2}^{-}$loss [33]. The ion of $\mathrm{m} / \mathrm{z} 191$ represents quinic acid, frequently found in higher plant as major compounds in the leaves [34] showed fragments of $\mathrm{m} / z 173$ after $\mathrm{H}_{2} \mathrm{O}$ loss [35]. The peak at $\mathrm{m} / \mathrm{z} 359$ was characterized as glycosyringic acid [36]. 3-Feruloylquinic acid (peak of $\mathrm{m} / \mathrm{z} 367$ ) was characterized according Fang et al. [37] and with fragment $\mathrm{m} / \mathrm{z}$ 173 and diagnostic peak $\mathrm{m} / z 193$ (hydroxymethoxycinnamoyl moiety). The peak at $m / z 463$ was characterized as mudanoside with fragments $\mathrm{m} / z 301\left([\mathrm{M}-\mathrm{H}-162]^{-}\right)$ lost glucose group [38].

Monogalloylglucose with its $m / z 331[\mathrm{M}-\mathrm{H}]^{-}$ion dissociating to yield an $\mathrm{m} / z 169$ ion after a glucosyl group loss ([M-H-162] $]^{-}$[ [39]. Digalloylglucose with its $m / z 483$ $[\mathrm{M}-\mathrm{H}]^{-}$ion dissociating to yield an $m / z 169$ ion after sequential removal of a galloyl group $\left([\mathrm{M}-\mathrm{H}-152]^{-}\right)$and a glucosyl group ([M-H-162]) [40].

HEEP and HEEA diagnostic mass fragments $m / z 301$ and $m / z \quad 317$ were characterized as quercetin and myricetin, respectively. The neutral losses of 132, 146 and 162 mass units allowed the identification of pentosides (xylose or arabinose), hexosides (glucose or galactose) and deoxyhexoside. Gallic acid was diagnosed by a neutral loss of 152 mass units. Peaks at $\mathrm{m} / \mathrm{z}$ 433, 447, 463, 593, 609, and 615 were assigned as flavonols and their derivatives. The quercetin pentoside isomer at $\mathrm{m} / \mathrm{z} 433$ $[\mathrm{M}-\mathrm{H}]^{-}$produced the MS/MS fragmentation of $m / z 300$ $[\mathrm{M}-\mathrm{H}-132]^{-}$, due the loss of arabinopyranoside. The ion at $m / z 447$ was tentatively assigned to quercetin-3-O- $\beta$ rhamnose. The MS/MS fragmentation produced a deprotonated aglycone ion at $\mathrm{m} / \mathrm{z} 301[\mathrm{M}-146-\mathrm{H}]^{-}$due loss a sugar moiety of $146 \mathrm{Da}$ and $\mathrm{m} / \mathrm{z} 271$ typical of flavon-3-O-monoglycoside [41] and 179 from RDA of ring A. Two isomeric compounds ions observed with $[\mathrm{M}-\mathrm{H}]^{-}$ at $m / z 463$, whose MS/MS main fragmentation produced a deprotonated aglycone form myricetin ion at $\mathrm{m} / z 317$ $[\mathrm{M}-146-\mathrm{H}]^{-}$(loss of a sugar moiety of 146 units), indicates that the compound is a myricetin monohexoside (myricetin 3-O-galactoside or myricetin 3-O-rhamnoside) and another isomer peak ion at $m / z 301$ with its $[\mathrm{M}-162-\mathrm{H}]^{-}$ (loss of a sugar moiety of 162 units), an indicative of quercetin monohexoside, and the hexose could be glucoside or galactoside [42]. Dissociation of fragment $\mathrm{m} / \mathrm{z} 593$ showed a loss of 308 units (corresponding to a rhamnose plus glucose group) and yielded directly a fragment ion at $m / z 285$ (assigned as kaempferol).

Compared to flavonoid glycosides found in gingko biloba [43], we tentatively characterized the compound as kaempferol-3-O- glucose- rhamnoside. Fragmentation 
of the compound at $\mathrm{m} / \mathrm{z} 609$ produced an ion at $\mathrm{m} / \mathrm{z}$ 301 , attributed to [M-H-146-162]- through loss of 308 units from a rhamnose $(146 \mathrm{u})$ plus a glucose $(162 \mathrm{u})$, indicating the compound is a rutin.

At $m / z 615$, the MS/MS peak fragmentation produced an ion at $m / z 463$ [M-152-H] (loss of the galloyl moiety) and a deprotonated quercetin at $m / z 301[\mathrm{M}-162-\mathrm{H}]^{-}$ (loss of a sugar moiety of 162 units), indicative of quercetin-3-O- $\beta-(6$ "galloyl) hexose. These flavonols derivatives have been previously reported in other Eugenia species and they are usually associated to antioxidant and antiproliferative activities [34, 39].

Some phenolic compounds found in HEEP/HEEA extracts belong to the family of ellagitannins. They are hydrolyzable tannins, a class of polyphenols whose structure consists of ellagic acid units linked to a polyol, usually glucose or quinic acid. These compounds are also characterized by their hexahydroxydiphenoyl (HHDP) group which is released on acid hydrolysis and spontaneously lactonizes to ellagic acid. Ellagic acid was characterized by diagnostic mass ion of $m / z 301$ and ma ss fragments at $m / z 257$ and 229 [40]. Ellagic acid xyloside was characterized by ion of $\mathrm{m} / \mathrm{z} 301$ [M-162-H] (loss of glucose plus $\mathrm{H}_{2} \mathrm{O}, 162$ units).

HHDP-glucose isomers were assigned as a signal at $\mathrm{m} /$ $z$ 481[M-162-18-H] (loss of glucose plus $\mathrm{H}_{2} \mathrm{O}, 180$ units) [33]. However, ellagitannins had lower efficacy in the inhibition of cell proliferation compared to ellagic acid, the breakdown product [44].

At $m / z 783$, the $\mathrm{MS}^{2}$ peak fragmentation produced an ion at $m / z 481$ [M-H-302] $]^{-}$, loss of HHDP), and after losing a HHDP-glucose $[\mathrm{M}-\mathrm{H}-481]^{-}$, an ion at $\mathrm{m} / z 301$ which corresponds to ellagic acid. This fragmentation pattern was assigned to a bis-HHDP-glucose isomer. Additionally there were peaks at $m / z 481[\mathrm{M}-\mathrm{H}-469]^{-}$, loss of a trisgalloyl group) and $m / z 301$, corresponding to ellagic acid. These results suggest a HDDP-glucose and a trigalloyl group. All those results are consistent with data reported for other Eugenia [42, 45].

Table 2 shows that EA contains the phenolic compounds myricitrin, rutin, quinic acid and quercetin derivatives. Among those compounds, some present a role on neutrophil activity. Aqueous extract containing quinic acid or its molecule derivate are described to inhibit neutrophil migration [46] and elastase secretion [47]. Despite inhibitory roles demonstrated for myricetin in elastase secretion [48], its derivate myricitrin does not present any inhibitory effect [49]. The suppressor character of rutin on neutrophil functions were better studied than the compounds cited above. Isolated rutin or the one found in plant extracts decreases in vitro and in vivo neutrophil migration [50], adhesion [51], elastase secretion [52] and NET release [27]. Quercetin derivatives were commonly found in E.aurata and E.punicifolia extract fractions. There are no evidences that quercetin-3-O- $\beta$-rhamanose or quercetin-galloyl-hexoside promotes effects on neutrophil activities. In contrast, quercetin suppresses elastase secretion [48] and in vivo and in vitro neutrophil migration [20]. The role of quercetin in the adhesion events is still unclear [53].

ESI-MS ${ }^{\mathrm{n}}$ analyses also revealed the presence of gallic acid, quercetin-3-O- $\alpha$-arabinopyranoside, syringic acid, ellagic acid, monogalloyl-glucose, glycosyringic acid, mudanoside B, HHDP glucose isomer and digalloylglucose isomer. The participation of these compounds in the neutrophil biology is poorly studied. There were reported downregulation of elastase secretion, NET release and neutrophil migration for gallic and ellagic acids present in plant extracts or in isolated form [53]. Evidences were not found for neutrophil adhesion.

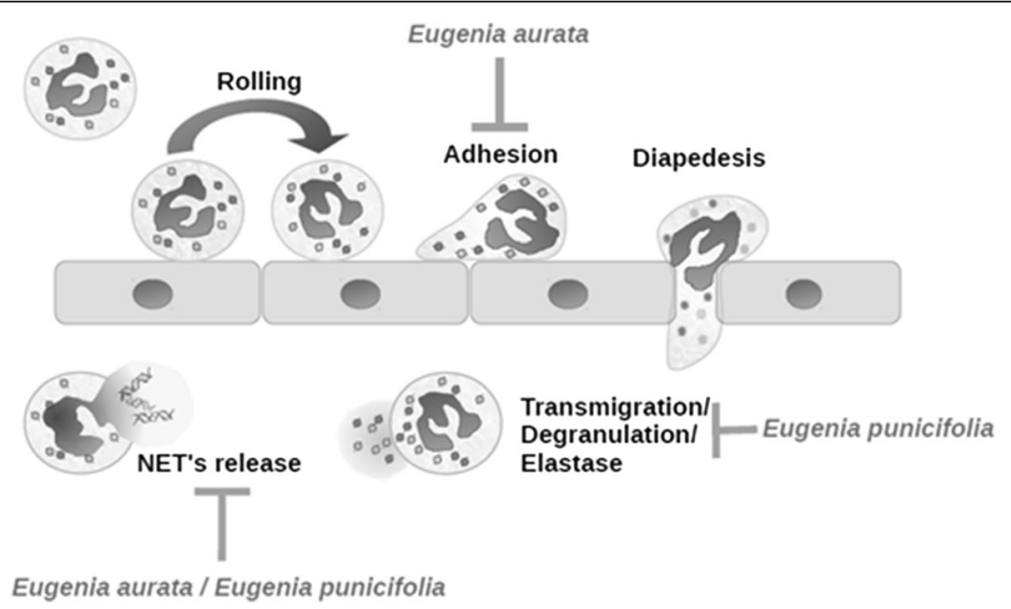

Fig. 6 Schematic summary of Eugenia aurata and E. punicifolia effects on neutrophil recruitment. EA affects mainly adhesion whereas EP, degranulation. Both extracts cease NETs release 


\section{Conclusions}

Based in our results, we are able to propose a model for the anti-inflammatory properties exhibited by both hydroethanolic extracts of E. aurata and E. punicifolia (Fig. 6). The extracts in this model have a different chemical composition in terms of phenolic compounds, but both present in vivo and ex vivo anti-inflammatory activity, besides not being toxic to neutrophils. E. aurata reduces neutrophil adhesion and E. punicifolia decreases elastase degranulation. NET release is inhibited by both extracts ex-vivo. Together, these effects result on a reduced inflammatory response and provide support to their use in popular medicine. Furthermore, these results show a potential of these extracts for the development of phytomedicines with anti-inflammatory properties, including the treatment of rheumatology, neoplastic, selfinflammatory, autoimmune or infectious disorders.

\section{Abbreviations}

DEX: Dexamethasone; DMSO: Dimethyl Sulfoxide; EA: E. aurata

hydroethanolic extract fraction soluble in PBS; EP: E.punicifolia hydroethanolic extract fraction soluble in PBS; ESI-MS: Electrospray ionization mass spectrometry; FBS: Fetal bovine serum; HEEA: E. aurata hydroethanolic extract solutions; HEEP: E. punicifolia hydroethanolic extract solutions; HPLC: High performance liquid chromatography; MTT: 3-(4,5-dimethylthiazol2-yl) 2,5-Diphenyl Tetrazolium bromide; NETs: Neutrophil extracellular traps; PBS: Phosphate Buffer Solution; PMA: Phorbol myristate acetate;

TG: Thioglycolate; TGl: Total growth inhibition

\section{Acknowledgments}

The authors acknowledge the biomedical Ivan Vicente Nascimento, the nurse Roseli Aparecida Vezenfard Soto and the Health Technical Section (FCL-Unesp) for their valuable help in blood sample acquisition. Also, Diogo Pessoa and Pedro Sampaio for english review.

\section{Funding}

This work was financially supported by Federal Brazilian agency CAPES (Coordenação de Aperfeiçoamento de Pessoal de Nível Superior).

\section{Availability of data and materials}

We have presented our primary data in the form of figure and tables. The datasets supporting the conclusions of this article are included within the article.

\section{Authors' contributions}

Conceived and designed the experiments: MFC, TIJ, BRPL, CFFA, AM, LPG, GSP, ALTGR, JEC, MNE, CS, KAT. Performed the experiments: MFC, TIJ, BRPL, CFFA, AM, LPG, GSP, ALTGR, JEC, MNE, CS. Analyzed the data: MFC, TIJ, BRPL, CFFA, AM, LPG, GSP, ALTGR, JEC, MNE, CS, KAT. Contributed reagents/ materials/analysis tools: CFFA, ALTGR, JEC, MNE, CS, KAT. Wrote the paper: MFC, TIJ, BRPL, CFFA, ALTGR, JEC, MNE, CS, KAT. All authors read and approved the final manuscript

\section{Competing interests}

The authors declare that they have no competing interests.

\section{Consent for publication}

All study participants provided informed consent for the data publication.

\section{Ethics approval and consent to participate}

Animal study was approved at the Animal Research Facility of the Faculdade de Ciências e Letras de Assis (FCLA) - UNESP. Proper authorization from the Ethics Committee (process no. 017/2012) permitted in vivo use of mice for neutrophil migration studies. For neutrophil isolation, the Ethics Committee on Human Research of the Faculdade de Ciências e Letras de Assis (FCLA) -, UNESP, approved the experimental protocol (number 020739120.0000 .5401 ). All participants provided written informed consent to participate in the study.

\section{Author details}

'Departamento de Ciências Biológicas, Faculdade de Ciências e Letras, Universidade Estadual Paulista -UNESP, Av Dom Antônio, 2100, Parque Universitário, ZIP 19806-900 Assis, SP, Brazil. ²ThoMSon Laboratório de Espectrometria de Massas, Instituto de Química, Universidade Estadual de Campinas (UNICAMP), Campinas 13083-970, Brazil. ${ }^{3}$ Centro Pluridisciplinar de Pesquisas Químicas, Biológicas e Agrícolas, UNICAMP, CP 6171, CEP 13083-970 Paulínia, SP, Brazil. ${ }^{4}$ Faculdade de Ciências Farmacêuticas, Universidade Estadual de Campinas (UNICAMP), P.O. Box 859, Campinas 13083-859, Brazil.

Received: 14 July 2016 Accepted: 4 October 2016

Published online: 22 October 2016

\section{References}

1. Kruger $P$, Saffarzadeh $M$, Weber AN, Rieber N, Radsak M, von Bernuth $H$, et al. Neutrophils: Between host defence, immune modulation, and tissue injury. PLoS Pathog. 2015;11(3):e1004651. doi:10.1371/journal.ppat.1004651.

2. Baliga MS. Anticancer, chemopreventive and radioprotective potential of black plum (Eugenia jambolana lam.). Asian Pac J Cancer Prev. 2011;12(1):3-15.

3. Rizvi SI, Mishra N. Traditional Indian medicines used for the management of diabetes mellitus. J Diab Res. 2013;2013:712092. doi:10.1155/2013/712092.

4. Lopes Galeno DM, Carvalho RP, Boleti AP, Lima AS, de Almeida PD O, Pacheco CC, et al. Extract from Eugenia punicifolia is an antioxidant and inhibits enzymes related to metabolic syndrome. Appl Biochem Biotechnol. 2014:172(1):311-24. doi:10.1007/s12010-013-0520-8.

5. Meyre-Silva C, Petry CM, Berte TE, Becker RG, Zanatta F, Delle-Monache F, et al. Phytochemical analyses and gastroprotective effects of Eugenia umbelliflora (Myrtaceae) on experimental gastric ulcers. Nat Prod Commun. 2009;4(7):911-6.

6. Leite PE, de Almeida KB, Lagrota-Candido J, Trindade P, da Silva RF, Ribeiro MG, et al. Anti-inflammatory activity of Eugenia punicifolia extract on muscular lesion of mdx dystrophic mice. J Cell Biochem. 2010;111(6):1652-60. doi:10.1002/jcb.22906.

7. Costa TR, Fernandes OF, Santos SC, Oliveira CM, Liao LM, Ferri PH, et al. Antifungal activity of volatile constituents of Eugenia dysenterica leaf oil. J Ethnopharmacol. 2000;72(1-2):111-7.

8. Grangeiro MS, Calheiros-Lima AP, Martins MF, Arruda LF, Garcez-do-Carmo L, Santos WC. Pharmacological effects of Eugenia punicifolia (Myrtaceae) in cholinergic nicotinic neurotransmission. J Ethnopharmacol. 2006;108(1):26-30. doi:10.1016/j.jep.2006.04.021.

9. Tenfen A, Siebert DA, Yamanaka CN, Mendes de Cordova CM, Scharf DR, Simionatto EL et al. Chemical composition and evaluation of the antimicrobial activity of the essential oil from leaves of Eugenia platysema. Nat Prod Res. 2015:1-5. doi:10.1080/14786419.2015.1107056

10. Maia JGS. Plantas aromáticas na Amazônia e seus óleos essenciais. Pará Brasil: Museu Paraense Emílio Goeldi; 2001.

11. Chaves E, Barros R. Diversidade e uso de recursos medicinais do carrasco na APA da Serra da Ibiapaba, Piauí, Nordeste do Brasil. Rev Bras Plantas Med. 2012;14(3):476-86

12. Silva SR. Plantas do cerrado utilizadas pelas comunidades da região do Grande Sertão Veredas. Brasília - Brasil: Funatura, Fundação Pró-Natureza, 1998.

13. Environment Mo. The state of the world's forest genetic resources, vol. 1. Brasília- Brazil: Minister of Environment; 2012. (acessed)

14. Garber JC, Barbee RW, Bielitzki JT, Clayton L, Donovan J, Hendriksen C, et al. Guide for the care and use of laboratory animals, vol. 8. Washington: The National Academic Press; 2011. p. 220.

15. Kabeya LM, Kanashiro A, Azzolini AE, Soriani FM, Lopes JL, Lucisano-Valim YM. Inhibitory effect of eight simple coumarins on the lucigenin enhanced chemiluminescence of rabbit neutrophils. Res Commun Mol Pathol Pharmacol. 2002;111(1-4):103-13.

16. Lucisano YM, Mantovani B. Lysosomal enzyme release from polymorphonuclear leukocytes induced by immune complexes of $\operatorname{lgM}$ and of IgG. J Immunol. 1984;132(4):2015-20.

17. Stocco B, Toledo K, Salvador M, Paulo M, Koyama N, Torqueti Toloi MR. Dosedependent effect of resveratrol on bladder cancer cells: chemoprevention and oxidative stress. Maturitas. 2012;72(1):72-8. doi:10.1016/j.maturitas.2012.02.004.

18. Sousa-Rocha D, Thomaz-Tobias M, Diniz LF, Souza PS, Pinge-Filho P, Toledo KA. Trypanosoma cruzi and Its Soluble Antigens Induce NET Release by Stimulating Toll-Like Receptors. PLoS One. 2015;10(10):e0139569. doi:10.1371/journal.pone.0139569. 
19. de Toledo KA, Bernardes ES, Baruffi MD, Roque-Barreira MC. Neutrophil haptotaxis induced by mouse MNCF: interactions with extracellular matrix glycoproteins probably contribute to overcoming the anti-inflammatory action of dexamethasone. Inflamm Res. 2007;56(9):368-76. doi:10.1007/s00011-007-6159-6.

20. Souto FO, Zarpelon AC, Staurengo-Ferrari L, Fattori V, Casagrande R, Fonseca MJ, et al. Quercetin reduces neutrophil recruitment induced by CXCL8, LTB4, and fMLP: inhibition of actin polymerization. J Nat Prod. 2011;74(2):113-8. doi:10.1021/np1003017.

21. Monks A, Scudiero D, Skehan P, Shoemaker R, Paull K, Vistica D, et al. Feasibility of a high-flux anticancer drug screen using a diverse panel of cultured human tumor cell lines. J Natl Cancer Inst. 1991;83(11):757-66.

22. Shoemaker $\mathrm{RH}$. The NCl60 human tumour cell line anticancer drug screen. Nat Rev Cancer. 2006:6(10):813-23. doi:10.1038/nrc1951.

23. Kalia K, Sharma K, Singh HP, Singh B. Effects of extraction methods on phenolic contents and antioxidant activity in aerial parts of Potentilla atrosanguinea Lodd. and quantification of its phenolic constituents by RPHPLC. J Agric Food Chem. 2008;56(21):10129-34. doi:10.1021/jf802188b.

24. Kolaczkowska E, Kubes P. Neutrophil recruitment and function in health and inflammation. Nat Rev Immunol. 2013;13(3):159-75. doi:10.1038/nri3399.

25. Fouche G, Cragg GM, Pillay P, Kolesnikova N, Maharaj VJ, Senabe J. In vitro anticancer screening of South African plants. J Ethnopharmacol. 2008;119(3): 455-61. doi:10.1016/j.jep.2008.07.005.

26. Degáspari C, Waszczynskyj N. Antioxidants properties of phenolic compounds. Visão Acadêmica. 2004;5(1):33-40.

27. Kirchner T, Hermann E, Moller S, Klinger M, Solbach W, Laskay T, et al. Flavonoids and 5-aminosalicylic acid inhibit the formation of neutrophil extracellular traps. Mediat Inflamm. 2013:2013:710239. doi:10.1155/2013/710239.

28. Friesenecker B, Tsai AG, Intaglietta M. Cellular basis of inflammation, edema and the activity of Daflon 500 mg. Int J Microcirc Clin Exp. 1995;15 Suppl 1:17-21.

29. Ferrandiz ML, Gil B, Sanz MJ, Ubeda A, Erazo S, Gonzalez E, et al. Effect of bakuchiol on leukocyte functions and some inflammatory responses in mice. J Pharm Pharmacol. 1996:48(9):975-80.

30. Magina MA, Gilioli A, Moresco HH, Colla G, Pizzolatti MG, Brighente IM. Atividade antioxidante de três espécies de Eugenia (Myrtaceae). Lat Am J Pharm. 2010;29(3):376-82.

31. Basting RT, Nishijima CM, Lopes JA, Santos RC, Lucena Perico L, Laufer $S$, et al. Antinociceptive, anti-inflammatory and gastroprotective effects of a hydroalcoholic extract from the leaves of Eugenia punicifolia (Kunth) DC. in rodents. J Ethnopharmacol. 2014;157:257-67. doi:10.1016/j.jep.2014.09.041.

32. Simirgiotis MJ, Borquez J, Schmeda-Hirschmann G. Antioxidant capacity, polyphenolic content and tandem HPLC-DAD-ESI/MS profiling of phenolic compounds from the South American berries Luma apiculata and L. chequen. Food Chem. 2013;139(1-4):289-99. doi:10.1016/j.foodchem.2013.01.089.

33. Regueiro J, Sanchez-Gonzalez C, Vallverdu-Queralt A, Simal-Gandara J, Lamuela-Raventos R, Izquierdo-Pulido M. Comprehensive identification of walnut polyphenols by liquid chromatography coupled to linear ion trapOrbitrap mass spectrometry. Food Chem. 2014;152:340-8. doi:10.1016/j. foodchem.2013.11.158

34. Oliveira AL, Destandau E, Fougere L, Lafosse M. Isolation by pressurised fluid extraction (PFE) and identification using CPC and HPLC/ESI/MS of phenolic compounds from Brazilian cherry seeds (Eugenia uniflora L.). Food Chem. 2014;145:522-9. doi:10.1016/j.foodchem.2013.08.065.

35. Fitzpatrick DF, Fleming RC, Bing B, Maggi DA, O'Malley RM. Isolation and characterization of endothelium-dependent vasorelaxing compounds from grape seeds. J Agric Food Chem. 2000;48(12):6384-90.

36. Ninh PT, Nhung LTH, Sung TV, Cuong NH, Thuy TT. Isolation and structural characterization of Phenolic glycoside and Triterpenes in Celastrus hindsii Benth. VJ Chem. 2008; 46(2).

37. Fang N, Yu S, Prior RL. LC/MS/MS characterization of phenolic constituents in dried plums. J Agric Food Chem. 2002;50(12):3579-85.

38. Lin H-C, Ding H-Y, Wu Y-C. Two Novel Compounds from Paeonia s uffruticosa. J Nat Prod. 1998;61(3):343-6.

39. Serna DM, Martinez JH. Phenolics and Polyphenolics from Melastomataceae Species. Molecules. 2015;20(10):17818-47. doi:10.3390/molecules201017818.

40. Lee JH, Johnson JV, Talcott ST. Identification of ellagic acid conjugates and other polyphenolics in muscadine grapes by HPLC-ESI-MS. J Agric Food Chem. 2005;53(15):6003-10. doi:10.1021/jf050468r.

41. Ablajan K, Abliz Z, Shang XY, He JM, Zhang RP, Shi JG. Structural characterization of flavonol 3,7-di-O-glycosides and determination of the glycosylation position by using negative ion electrospray ionization tandem mass spectrometry. J Mass Spectrom. 2006;41(3):352-60. doi:10.1002/jms.995

42. Sales DS, Carmona F, de Azevedo BC, Taleb-Contini SH, Bartolomeu AC, Honorato FB, et al. Eugenia punicifolia (Kunth) DC. as an adjuvant treatment for type-2 diabetes mellitus: a non-controlled, pilot study. Phytother Res. 2014;28(12):1816-21. doi:10.1002/ptr.5206.

43. Zhou H, Tang W, Zeng J, Tang C. Screening of terpene lactones and flavonoid glycosides in Gingko biloba capsule by UPLC-Orbitrap high resolution MS, with emphasis on isomer differentiation. J Food Nutr Res. 2014;2(7):369-76.

44. Pinto Mda S, de Carvalho JE, Lajolo FM, Genovese MI, Shetty K. Evaluation of antiproliferative, anti-type 2 diabetes, and antihypertension potentials of ellagitannins from strawberries (Fragaria $x$ ananassa Duch.) using in vitro models. J Med Food. 2010;13(5):1027-35. doi:10.1089/jmf.2009.0257.

45. Yang LL, Lee $C Y$, Yen $K Y$. Induction of apoptosis by hydrolyzable tannins from Eugenia jambos L. on human leukemia cells. Cancer Lett. 2000;157(1):65-75.

46. Schinella G, Neyret E, Console G, Tournier H, Prieto JM, Rios JL, et al. An aqueous extract of llex paraguariensis reduces carrageenan-induced edema and inhibits the expression of cyclooxygenase-2 and inducible nitric oxide synthase in animal models of inflammation. Planta Med. 2014;80(12):961-8. doi:10.1055/s-0034-1382876.

47. Benedek B, Kopp B, Melzig MF. Achillea millefolium L. s.l. - is the antiinflammatory activity mediated by protease inhibition? J Ethnopharmacol. 2007;113(2):312-7. doi:10.1016/j.jep.2007.06.014.

48. Kanashiro A, Souza JG, Kabeya LM, Azzolini AE, Lucisano-Valim YM. Elastase release by stimulated neutrophils inhibited by flavonoids: importance of the catechol group. Z Naturforsch C. 2007;62(5-6):357-61.

49. Xu GH, Ryoo IJ, Kim YH, Choo SJ, Yoo ID. Free radical scavenging and antielastase activities of flavonoids from the fruits of Thuja orientalis. Arch Pharm Res. 2009;32(2):275-82. doi:10.1007/s12272-009-1233-y.

50. Chen WY, Huang YC, Yang ML, Lee CY, Chen CJ, Yeh CH, et al. Protective effect of rutin on LPS-induced acute lung injury via down-regulation of MIP2 expression and MMP-9 activation through inhibition of Akt phosphorylation. Int Immunopharmacol. 2014;22(2):409-13. doi:10.1016/j. intimp.2014.07.026.

51. Suyenaga ES, Klein-Junior LC, Passos Cdos S, Marin R, Santin JR, Machado ID, et al. Beyond organoleptic characteristics: the pharmacological potential of flavonoids and their role in leukocyte migration and in L-selectin and beta2integrin expression during inflammation. Phytother Res. 2014;28(9):1406-11. doi:10.1002/ptr.5144.

52. Vasange M, Liu B, Welch CJ, Rolfsen W, Bohlin L. The flavonoid constituents of two Polypodium species (Calaguala) and their effect on the elastase release in human neutrophils. Planta Med. 1997;63(6):511-7. doi:10.1055/s-2006-957753.

53. Suri S, Taylor MA, Verity A, Tribolo S, Needs PW, Kroon PA, et al. A comparative study of the effects of quercetin and its glucuronide and sulfate metabolites on human neutrophil function in vitro. Biochem Pharmacol. 2008;76(5):645-53. doi:10.1016/j.bcp.2008.06.010.

\section{Submit your next manuscript to BioMed Central and we will help you at every step:}

- We accept pre-submission inquiries

- Our selector tool helps you to find the most relevant journal

- We provide round the clock customer support

- Convenient online submission

- Thorough peer review

- Inclusion in PubMed and all major indexing services

- Maximum visibility for your research

Submit your manuscript at www.biomedcentral.com/submit
) Biomed Central 